\title{
MAIORIDADE PENAL: POLÍTICA OU IDEOLOGIA
}

\section{Bruna Fernanda Rodrigues Correia, Michele Galhardo}

Universidade do Oeste Paulista - UNOESTE, curso de Direito, Presidente Prudente, SP. E-mail: michele.galhardo@hotmail.com

\section{RESUMO}

A Maioridade penal é um assunto bastante polêmico e atual entre os juristas e a sociedade em geral, com inúmeros questionamentos no âmbito político social e legal. A mídia por sua vez, mostra os conflitos sociais de maneira exagerada, dividindo a sociedade em opiniões favoráveis e desfavoráveis a redução da maioridade penal. É nítido um "plus" na participação de adolescentes no meio criminoso. Logo a sociedade se coloca cada vez mais a favor dessa mudança como solução para o problema. Diante do contexto, podemos analisar o Direito penal coercitivo como mantenedor da ordem social e a ausência do Estado na promoção de condições dignas e eficazes. Devemos levar em conta todos os fatores que aumentam à criminalidade, logo, a redução é a solução?

Palavras-chave: Maioridade penal, redução, solução, Estado, polêmico, políticas sociais.

\section{CRIMINAL MAJORITY: POLITICAL OR IDEOLOGY}

\begin{abstract}
The penal Majority is a very controversial issue and current between lawyers and the society at large with numerous questions under social political and legal. The media in turn shows the social conflicts exorbitantly dividing society into favourable and unfavourable reviews the reduction of majority. It's clearly a plus on participation of adolescents in the kind of criminal. Soon the company arises increasingly in favor of this change as a solution to the problem. On the context we can analyze the coercive criminal law as maintainer of the social order and the absence of the State in promoting decent conditions and effective. We must take into account all the factors that increase crime, so the reduction is the solution?
\end{abstract}

Keywords: Majority, reduction, criminal, State solution, controversial social policies. 


\section{INTRODUÇÃO}

A maioridade penal foi uma preocupação durante décadas para os juristas pátrios o qual não havia critérios de segurança para definir o liame da idade penal, com a Constituição Federal de 1988 e a criação de norma constitucional que tratasse da maioridade, trouxe um avanço ao sistema penal brasileiro ao instituir 18 anos como marco para imputar a pratica de um fato punível. O nosso sistema constitucional brasileiro em seu art. 228 dispõe que:

Art. 228. São penalmente inimputáveis os menores de dezoito anos, sujeito às normas da legislação especial.

A maioridade penal encontra-se inscrita em outros dois diplomas legais: artigo 27 do Código Penal, e artigo 104 caput do Estatuto da Criança e do Adolescente.

O trabalho em tela terá como ponto de partida apresentação de alguns conceitos, para que haja melhor compreensão sobre o assunto. Faz-se necessário entende-los, já que os mesmo estão diretamente relacionados à maioridade penal e ao que será discutido a diante.

Posteriormente, será feito levantamento doutrinários quanto aos posicionamentos pós e contras à redução da maioridade penal.

Ainda será exposto, o impacto da redução da maioridade penal na sociedade civil, o aparato ineficaz do Estado nas políticas públicas, e a interferência da mídia nesses casos.

\section{METODOLOGIA}

O estudo em tela será desenvolvido mediante o método dedutivo modalidade de raciocínio lógico que faz uso da dedução através de levantamento bibliográfico, leitura, fichamento e artigos eletrônicos. Buscar-se-á um estudo e apresentação da problemática, partindo do raciocínio legalista, sociológico, critico e político; e estudos de como são regidas as normas que visam à redução da maioridade penal; daquilo que de mais interessante se pode levantar sobre a matéria em debate. Os dados apresentados serão questionados, interpretados e debatidos para maior clareza e formação de opinião.

\section{CONCEITOS PRINCIPAIS}

O presente estudo visa entendermos melhor sobre alguns aspectos e elementos da inimputabilidade no sistema penal brasileiro, para auferirmos o pretendido neste trabalho.

Bitencourt defini inimputabilidade como:

Pode-se afirmar, de forma genérica, que estará presente a imputabilidade, sob a ótica do Direito Penal brasileiro, toda vez que o agente apresentar condições de 
normalidade e maturidade psíquicas mínimas para que possa ser considerado como um sujeito capaz de ser motivado pelos mandados e proibições normativos. (2013, p.474)

Para Damásio de Jesus:

O menor de dezoito anos não possui maturidade suficiente para responder pelos seus atos, ainda o seu reconhecimento depende de aptidão biopsíquica para conhecer a ilicitude do fato quando cometido por ele para determinar esse entendimento. Assim sendo, a responsabilização do menor de dezoito anos segundo a o artigo 228 caberá sobre uma legislação especial, encerrando assim uma garantia de não aplicação do direito penal, conseqüentemente, todas as cláusulas pétreas garantidas pelo artigo 60 da Constituição Federal. (1985 p. 400)

O Direito Penal brasileiro adotou o sistema biopsicológico para constatar a inimputabilidade. Tais indivíduos, independentemente do desenvolvimento mental, são considerados inimputáveis mesmo que sejam emancipados, a inimputabilidade é absoluta (iuris et de iure), decorre de norma constitucional. Isso, contudo não significa que o menor de dezoito anos não seja responsabilizado de alguma forma pela infração cometida. De acordo com a lei 8.069/90 (Estatuto da Criança e do Adolescente - entre 12 e 18 anos) responderá pelo ato infracional, sendo the aplicável medida socioeducativa.

Ao se discutir a maioridade penal acalorado debates são instituídos, a quem diga que as medidas socioeducativas são brandas e ineficazes, quanto ao combate à ilicitude outros tangem aos direitos humanos que redução é uma medida radical e culpa o Estado por sua omissão. Além do que, mesmo que alguns digam ser possível a redução da maioridade penal por emenda constitucional, pois, não estaria abolindo o direito e garantia fundamental, no entanto, traria uma insegurança jurídica necessária à existência de um Estado Democrático de Direito.

A seguir serão apresentadas as controvérsias da redução da Maioridade Penal.

\section{O CAOS DA REDUÇÃO DA MAIORIDADE PENAL}

As divulgações dos atos infracionais cometidos por jovens infratores não correspondem, e tampouco superam os dos adultos assim como a mídia tem destacado e noticiado, dando a impressão de ser uma pratica comum o qual é uma inverdade. Aduz o aludido mestre Miguel Reale Junior, o seguinte pensamento:

Os adolescentes são muito mais que vitimas de crimes do que autores, contribuindo este fato para a queda da expectativa de vida no Brasil, pois se existe um "risco Brasil" este reside na violência da periferia das grandes e medias cidades. Dado impressionante é o de que $65 \%$ dos infratores vivem em família desorganizada, 
junto com a mãe abandonada pelo marido, que por vezes tem filhos de outras uniões também desfeitas e luta para dar sobrevivência à sua prole. (2009- p. 212).

Há autores, assim como Zaffaroni, que ressaltam o caráter demagógico da redução da maioridade penal como solução:

O novo "popularismo penal" [...] é uma demagogia que explora o sentimento de vingança das pessoas, mas, politicamente falando, é uma nova forma de autoritarismo. A violência aumenta porque aumentou a miséria. Os anos 1990 foram os anos do festival do mercado: os pobres ficaram mais pobres e alguns ricos, nem todos, mais ricos. Os mesmos autores dessa política de polarização da sociedade são os que hoje pedem mais repressão sobre os setores vulneráveis da população. [...] No final, eles não são vulneráveis a essa violência. A "guerra" que pedem é a "guerra" entre pobres. [...] Essa política dos chamados comunicadores sociais e dos políticos sem programa, que só querem mais poder policial, no fundo é a neutralização da incorporação das maiorias à democracia. (2007, p. 131).

A violência e a criminalidade estão diretamente relacionadas com a pobreza, à miséria cultural e o enfraquecimento do estado democrático de direito como garantia fundamental. Aqueles que defendem a redução da idade penal não pensam na proteção dos adolescentes marginalizados e por muitas vezes esquecido por um sistema sem acesso a educação, saúde, segurança e alimentação, garantias que muitos (legisladores) esquecem, e leigos desconhecem que possui respaldo na lei maior do País, constante no art. 227, caput, CF:

Art. 227: É dever da família, da sociedade e do Estado assegurar a criança, e ao adolescente e ao jovem, com absoluta prioridade, o direito a vida, à saúde, à alimentação, à educação, ao lazer, à profissionalização, à cultura, a dignidade, ao respeito, à liberdade e à convivência familiar e comunitária, além de colocá-los ao salvo de toda forma de negligência, discriminação, exploração, violência crueldade e opressão.

E um, em meio a tantos, objetivos fundamentais da Constituição Federal, é a contra senso ao que se vê nos dias atuais, a erradicação da pobreza e a marginalização, além de construir uma sociedade justa, livre e solidaria, conforme art. 3 a da referida Carta.

As pesquisas indicam que não há nexo de causalidade em relação à diminuição da maioridade penal e a diminuição da violência, que ao contrário, só fariam com que cada vez mais cedo essas crianças fossem aliciadas para uma vida delituosa.

\section{CONDIÇÕES DO SISTEMA PRISIONAL}

Outro problema presente em nossa realidade é quanto ao sistema prisional brasileiro, que se encontra falido, superlotado e abandonado pelo Estado, fato que vem se agravando em nossa 
sociedade. As consequências do mau funcionamento deste sistema são percebidas nitidamente em meio à população, aumentando assim o índice de criminalidade pelos egressos reincidentes. Isto acontece, por que, o sistema carcerário de hoje é considerado uma "fabrica" de criminosos, quando na verdade estes encarcerados deveriam de forma profissionalizante preparar-se para reabilitação, já que a pena privativa de liberdade possui a finalidade de recolher o individuo a custodia do Estado, e devolvelos para sociedade reabilitados.

Todavia, com base na falência desse sistema, sabendo que o regime de pena privativa de liberdade não atinge sua finalidade com os encarcerados adultos, o que dizer com relação aos jovens infratores que não possuem maturidade, discernimento biopsicológico suficiente para responderem por seus atos? Como inserir um adolescente num sistema como este? Como uma mãe dormiria sabendo que seu filho esta em um lugar onde ele aprendera ainda mais sobre criminalidade?

No mês de Julho/2015 os senadores aprovaram projeto para aumentar o tempo de internação para dez anos, de menores infratores que cometem crimes hediondos e homicídio doloso. $\mathrm{O}$ texto apresenta um regime especial de atendimento socioeducativo dentro do Estatuto da Criança e do Adolescente. O projeto também prevê que os menores infratores que cometerem crimes graves fiquem em uma ala separada dos demais. Em outra frente, a proposta também endurece a pena de adultos que usarem menores para praticar crimes. Para aqueles que são contra a redução da maioridade penal, o que se espera são medidas como estas, tomas pelo Estado. É nisto que se acredita. Tal projeto ainda esta em fase de aprovação, será agora encaminhado para Câmara dos Deputados para apreciação da Casa.

\section{CONCLUSÃO}

Diante do exposto, é mister afirmarmos que a redução da maioridade penal não diminui os índices de violência, e tampouco é a solução para um problema que surge das desigualdades sociais.

A criança e o adolescente que ingressam na vida, criminosa muitas vezes marginalizados por uma sociedade omissa, perde mais que sua liberdade, perde sua infância, seus sonhos e entrega sua vida e sua alma ao crime que muitas vezes acaba com a morte.

A função principal das penas privativas de liberdade é a ressocialização daquele egresso a sociedade, no entanto nosso sistema prisional não possui aparato suficiente para reinserção desse detento ao convívio social e tampouco a sociedade encontra-se preparada para recebê-los.

O clamor popular ainda é constante pelo endurecimento de penas, no entanto, o que se percebe é uma manobra extremamente politica de governantes procurando atender aos anseios de $80 \%$ de uma 
sociedade que a contra senso é leiga em relação às medidas socioeducativas aplicadas pelo ECA, que em geral muitos ainda desconhecem o que este rege.

Todavia, não podemos nos deixar influenciar por tais ideologias politicas, pois vivemos em um Estado Democrático de Direito que deve prezar pelas garantias e liberdades individuais que foram construídas arduamente durante décadas de luta.

\section{REFERÊNCIAS}

BITENCOURT, C. R. Tratado de Direito Penal. Parte Geral. 19ạ Edição. São Paulo: Editora Saraiva, 2013.

JESUS, D. E. de. Direito penal. Parte Geral. 10a Edição. São Paulo: Editora Saraiva, 1985.

LENZA, P. Direito Constitucional Esquematizado. 18a edição, São Paulo: Editora Saraiva, 2014.

REALE, M. Nova Fase do Direito Moderno. São Paulo: Saraiva. 2001.

REALE Jr., M. Instituições de Direito Penal. 3a Edição. Rio de Janeiro: Editora Forense, 2009.

ESTADÃO. Senadores aprovam projeto para aumentar tempo de internação de menores infratores. Disponível em: http://zh.clicrbs.com.br/rs/noticias/noticia/2015/07/senadores-aprovam-projeto-paraaumentar-tempo-de-internacao-de-menores-infratores-4802010.html. Acessado em: 19 ago.2015.

ROCHA, S. B. da. A redução da maioridade penal. Disponível em: http://ambitojuridico.com.br/site/?n_link=revista_artigos_leitura\&artigo_id=13332\&revista_caderno=12\#_ftn1 1. Acessado em 18 ago. 2015.

VITURIANO, T. M., A falácia da redução da maioridade penal como solução para a problemática da criminalidade. Disponível em: http://ambitojuridico.com.br/site/?n_link=revista_artigos_leitura\&artigo_id=14107. Acessado em 18 ago. 2015. 